\title{
Implementasi Karakteristik Nilai Kalor Briket Campuran Limbah Kulit Durian dan Tempurung Kelapa pada Pembelajaran Suhu dan Kalor Di SMP N 15 Kota Bengkulu
}

\author{
Eva Suryani $^{1,3}$, Muhammad Farid ${ }^{2}$, Afrizal Mayub ${ }^{1}$ \\ ${ }^{1}$ Pascasarjana Pendidikan IPA FKIP Universitas Bengkulu \\ ${ }^{2}$ Jurusan Fisika FMIPA Univesitas Bengkulu \\ ${ }^{3}$ SMP N 15 Kota Bengkulu \\ *E-mail: evas33893@gmail.com
}

DOI: https://doi.org/10.33369/pendipa.3.3.146-153

\begin{abstract}
[Implementation of The Characteristics of the Heating Value of Briquettes in a Mixture of Durian Skin and Coconut Shell Waste in Temperature and Heat Learning In SMPN 15 Bengkulu City]. This study aims to determine the characteristics and calorific value briquettes mix variations durian peel and coconut shell and knowing the increase in students cognitive learning outcomes after using briquettes as a practicum material on the temperature and heat material by using a model of Discovery Learning (DL) in SMP N 15 Bengkulu City. The type of research in used quasi eksperiment. The sampele in this study was extra curricular student class VII in SMP N 15 Bengkulu City. The calorific value of the briquette mixture of durian peel and coconut shell is determined by using the tool Bomb Calorimeter Chemistry Laboratory Basic Science UNIB and characteristics of the briquette was done Science Laboratory og SMPN 15 Bengkulu City. In this study, the skin of durian mixed Science Laboratory og SMPN 15 Bengkulu Citywith coconut shell with the composition (1) $20 \%$ of skin durian: $80 \%$ coconut shell; (2) $50 \%$ of the durian skin: $50 \%$ coconut shell and (3) 80\% of the durian skin: $20 \%$ coconut shell.Data collection techniques in the implementation of such lerning achievement test in the form of multiple-choise has been validated. Results of research on the calorific value of the mixture at (1) amounted to $7306.81 \mathrm{cal} / \mathrm{gram}$, at (2) amounting to $6487.31 \mathrm{cal} /$ gram and in (3) of $6284.99 \mathrm{cal} / \mathrm{gram}$. Characteristics of briquettes include water content was lost, the density of the briquettes and burning speed. Based on the results of dataprocessing showed that after learning by using the model of Discovery Learning (DL), cognitive learning outcomes of students has increased and the value of $N$-gain for the high grade was 0.78 in the high category, the group is sebesa 0.57 in the medium category and the lower group was 0.53 in the medium category.
\end{abstract}

Keywords: Charcoal briquettes; calorific value; characteristics of briquettes; Discovery Learning

(Received July 13, 2019; Accepted August 7, 2019; Published October 22, 2019)

\begin{abstract}
ABSTRAK
Penelitian ini bertujuan untuk menentukan karakteristik dan nilai kalor briket variasi campuran kulit durian dan tempurung kelapa dan mengetahui peningkatan hasil belajar kognitif siswa setelah menggunakan briket sebagai bahan praktikum pada materi suhu dan kalor dengan menggunakan model Discovery Learning di SMP N 15 Kota Bengkulu. Jenis penelitian yang digunakan yaitu quasi eksperimen. Sampel dalam penelitian ini yaitu siswa kelas VII ekstra kurikuler KIR SMP N 15 Kota Bengkulu. Data nilai kalor briket campuran kulit durian dan tempurung kelapa ditentukan dengan menggunakan alat Bomb Calorimeter di Laboratorium Kimia Basic Science UNIB dan karakteristik briket di lakukan di Laboratorium IPA SMP N 15 Kota Bengkulu. Dalam penelitian ini kulit durian dicampur dengan tempurung kelapa dengan komposisi (1) 20\% kulit durian: $80 \%$ tempurung kelapa; (2) 50\% kulit durian: 50\% tempurung kelapa dan (3) 80\% kulit durian: $20 \%$ tempurung kelapa. Tehnik pengumpulan data pada implementasi pembelajaran berupa tes hasil belajar dalam bentuk pilihan ganda yang telah divalidasi. Hasil penelitian nilai kalor pada campuran (1) sebesar 7306,81 kal/gram, pada campuran (2) sebesar 6487,31 kal/gram dan pada campuran (3) sebesar 6284,99 kal/gram. Karakteristik briket meliputi kadar air hilang, kerapatan briket, kecepatan pembakaran
\end{abstract}


briket. Berdasarkan hasil pengolahan data menunjukkan bahwa setelah belajar dengan menggunakan model Discovery Learning (DL) hasil belajar kognitif peserta didik mengalami peningkatan dan nilai $\mathrm{N}$-gain untuk kelas tinggi adalah sebesar 0,78 dalam kategori tinggi, kelompok sedang sebesa 0,57 dalam kategori sedang dan kelompok rendah sebesar 0,53 dalam kategori sedang.

Kata Kunci: Briket arang; nilai kalor; karakteristik briket; Discovery Learning

\section{PENDAHULUAN}

Menipisnya cadangan atau sumber bahan bakar minyak, mendorong manusia untuk mencari dan mengembangkan sumber energi alternatif pengganti bahan bakar minyak yakni sumber energi terbarukan. Sumber energi terbarukan dapat berasal dari biomassa. Teknologi pengolahan biomassa menjadi sumber energi dibuat dengan menjadikannya briket arang, dimana biomassa diolah menjadi arang terlebih dahulu belum dicetak menjadi briket (Emerchi, 2011). Salah satu biomassa limbah padat yang belum banyak dimanfaatkan adalah limbah dari pertanian khususnya limbah kulit durian dan tempurung kelapa.

Durian merupakan tumbuhan tropis yang berasal dari Asia Tenggara memiliki rasa yang banyak disukai masyarakat dari berbagai kalangan (Nuriana et al, 2013; Hasbullah et al, 2018). Masyarakat Indonesia khususnya masyarakat Bengkulu hanya mengkonsumsi daging buah durian saja sedangkan kulitnya terbuang dan menjadi limbah yang memberikan masalah dilingkungan.

Limbah kulit durian dapat dimanfaatkan menjadi sumber energi alternatif dengan menjadiknya briket. Menurut Hatta (2007) nilai kalor briket kulit durin sebesar 3.786,95 $\mathrm{kal} /$ gram. Nilai kalor kulit durian ini masih dibawah standar SNI sbesar $5.000 \mathrm{kal} / \mathrm{gram}$. Nilai kalor kulit durian ini meningkat jika dicampur dengan nilai kalor biomasa yang tinggi. Biomassa dengan nilai kalor tinggi biasanya dijadikan sebgai basis pencampuran dalam pembuatan briket (Nurhilal et al, 2018). Biomassa yang digunakan sebagai pencampur briket dalam penelitian ini yaitu tempurung kelapa.

Penelitian yang di lakukan Langkai et al (2015) hanya menguji waktu pembakaran briket limbah kulit durian kombinasi tempurung kelapa (2:1) dan limbah kulit durian kombinasi tempurung kelapa (1:1). Penelitian ini merupakan lanjutan dari penelitian yang dilakukan Langkai et al (2015) yakni pengujian nilai kalor briket limbah kulit durian dan tempurung kelapa dengan komposisi yang berbeda-beda yaitu komposisi $20 \%$ arang kulit durian: $80 \%$ arang tempurung kelapa; $50 \%$ arang kulit durian: 50\% arang tempurung kelapa dan $80 \%$ arang kulit durian: $20 \%$ arang tempurung kelapa. Perbedaan penelitian yang dilakukan dengan penelitian Langkai et al (2015) terletak pada penambahan komposisi, menentukan karakteristik briket campuran kulit durian dan tempurung kelapa serta menentukan nilai kalor briket campuran kulit durian dan tempurung kelapa.

Briket campuran kulit durian dan tempurung kelapa merupakan teknologi pengembangan bahan bakar alternatif. Briket dapat dimanfaatkan oleh masyarakat sebagai bahan bakar pengganti BBM dan kayu untuk memasak dan bagi ilmu pengetahuan sebagai media pembelajaran IPA sumber bahan bakar dalam praktikum. Pemanfaatan Briket sebagai bahan bakar dalam praktikum IPA, memberikan pengalaman lansung kepada siswa dalam memahami materi suhu dan kalor. Menurut Putri et al (2017) Proses pembelajaran IPA menekankan pada pemberian pengalaman lansung untuk mengembangkan kompetensi agar menjelajahi dan memahami alam sekitar secara ilmiah. metode pembelajaran yang dapat menekankan pada pembelajaran siswa aktif dalam menemukan konsep sendiri diantaranya metode Discovery Learning (Kemendikbud, 2013).

Model pembelajaran yang digunakan dalam penelitian ini adalah model pembelajaran Discovery Learning. Pemilihan model pembelajaran Discovery Learning ini untuk memotivasi siswa belajar sendiri secara mandiri, mudah dilakukan dan menyenangkan, sehingga diharapkan dapat menarik minat siswa untuk berpartisipasi aktif dalam pembelajaran konsep suhu dan kalor untuk memperoleh pengalaman lansung menetukan nilai kalor briket campuran 
kulit durian dan tempurung kelapa. Penerapan pembelajaran penemuan memiliki kelebihan membantu siswa untuk memperbaiki dan meningkatkan keterampilan dan proses kognitif dalam hal ini hasil belajar.

Tujuan dari penelitian adalah untuk (1) mendiskripsikan nilai kalor briket variasi campuran limbah kulit durian dan tempurung kelapa. (2) mendiskripsikan karakteristik briket variasi campuran limbah kulit durian dan tempurung kelapa meliputi kadar air hilang, kerapatan briket, kecepatan pembakaran dan total kalor briket terpakai. (3) mendiskripsikan peningkatan hasil belajar kognitif siswa setelah menggunakan briket sebagai bahan praktikum pada materi suhu dan kalor dengan menggunakan model Discovery Learning di SMP N 15 Kota Bengkulu.

\section{METODOLOGI PENELITIAN}

Jenis penelitian yang dilakukan dalam penelitian ini yakni quasi eksperiman. Tahap quasi eksperimen dalam penelitian ini meliputi pra implementasi, implementasi dan pasca implementasi. Tahap pra implementasi dilakukan penelitian sains. Penelitian sains yang akan dilakukan berupa penelitian eksperimen lansung yang bertujuan untuk mendeskripsikan nilai kalor briket campuran kulit durian dan tempurung kelapa. Hasil penelitian sains berupa briket akan di implikasikan pada penelitian pendidikan dimana briket digunakan sebagai bahan praktikum didalam pembelajaran IPA materi Suhu dan Kalor meningkatkan hasil belajar siswa.

Penelitian dilakukan di Laboratorium IPA SMP N 15 Kota Bengkulu dan penentuan nilai kalor briket variasi campuran kulit durian dan tempurung kelapa dilakukan di laboratorium Kimia Basic Science Universitas Bengkulu mulai bulan Desember sampai dengan bulan Maret 2019.

1. Tahap Pra Implementasi/Persiapan. Pada tahap ini dilakukan penelitian sains yaitu pembuatan briket campuran limbah kulit durian dan tempurung kelapa dengan komposisi yang berbeda-beda.

\section{Bahan dan alat}

Bahan baku yang digunakan dalam pembuatan briket adalah arang kulit durian, arang tempurung kelapa dan larutan tepung tapioka. Alat yang digunakan dalam penelitian ini drum, alat cetak briket, saringan (ayakan), timbangan digital, tumbukan batu dan tungku tanah.

\section{Tahap Penelitian}

Limbah kulit durian dan tempurung kelapa yang sudah didapatkan dikeringkan dibawah sinar matahari. Setelah pengeringan kulit durian dan tempurung kelapa diarangkan. Kulit durian dan tempurung kelapa diarangkan dengan cara terpisah. Mengarangkan kulit durian dan tempurung kelapa dengan menggunakan drum bekas yang telah bersih. Tahapan pengarangan dilakukan membakar bahan didalam drum, kemudian drum ditutup selama 1 malam sampai menjadi arang.

Setelah menjadi arang bahan dihaluskan dengan dengan menggunakan tumbukan batu dan diayak dengan ayakan untuk mendapatkan ukuran yang sama. Selanjutnya campuran arang kulit durian dan tempurung kelapa dengan komposisi 20\%:80\%; 50\%:50\% dan 80\%:20\%. Proses selanjutnya melakukan pencampuran dengan bahan perekat larutan tepung tapioka selanjutnya dilakukan pencetakan. Briket yang didapatkan dikeringkan dibawah sinar matahari selama 4 hari. Dari variasi pencampuran tersebut dilakukan pengujian nilai kalor dan karakteristik briket meliputi kadar air hilang, kerapatan briket, kecepatan pembakaran.

Nilai kalor briket ditentukan dengan alat Bomb Calorimeter di Laboratorium Kimia Basic Science Universitas Bengkulu.

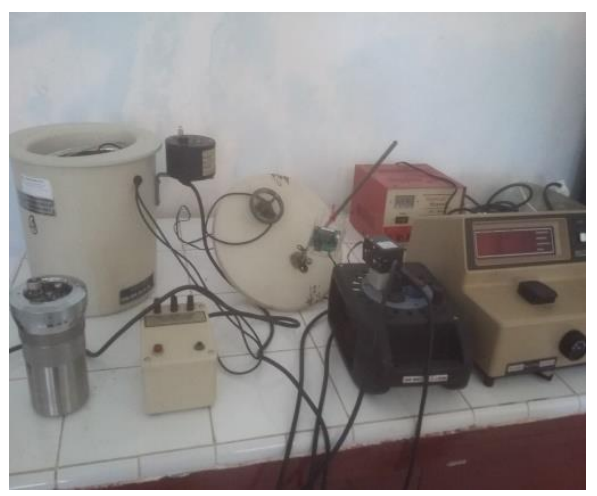

Gambar 1. Bomb Calorimeter 
Karakteristik Briket meliputi:

\section{a.Kadar Air Hilang $(K A h)$}

Kadar air hilang merupakan persentase dari selisih massa briket sebelum dipanaskan $\left(\mathrm{m}_{1}\right)$ dengan massa briket setelah pemanasan $\left(\mathrm{m}_{2}\right)$ terhadap massa briket sebelum dipanaskan $\left(\mathrm{m}_{1}\right)$. Menurut Yuliah et al (2017) kadar air hilang dapat dihitung dengan menggunakan persamaan:

$$
K A_{\text {hilang }}=\frac{m_{1}-m_{2}}{m_{1}} x 100 \%
$$

\section{b.Kerapatan $(\rho)$}

Kerapatan merupakan massa briket setelah dipanaskan (m) terhadap volume briket (V). Menurut Yuliah et al (2017) kerapatan dapat dihitung dengan menggunakan persamaan:

$$
\rho=\frac{m}{V}
$$

c.Briket Terpakai ( Fcd)

Merupakan jumlah biobriket yang terpakai selama memasak air hingga mendidih $100 \%$. Dihitung dengan mengurangkan bionriket awal yang dibakar $\left(\mathrm{F}_{\mathrm{ci}}\right)$ dengan berat sisa biobriket $\left(\mathrm{F}_{\mathrm{cf}}\right)$ (Fajari, 2012)

$$
\mathrm{F}_{\mathrm{cd}}=\mathrm{F}_{\mathrm{ci}}-\mathrm{F}_{\mathrm{cf}}
$$

\section{d. Waktu Untuk Memasak (Td)}

Dihitung lama waktu dalam memasak air mulai dari peletakan panci hingga air mendidih sempurna $100^{\circ} \mathrm{C}$ (Fajari, 2012).

\section{e.Kecepatan pembakaran Biobriket ( Rcb)}

Merupakan banyak biobriket yang terpakai ( Rcb) perwaktu mendidihkan air ( td) dengan satuan g/ menit ( Fajari, 2012)

$$
\mathrm{R} \mathrm{cb}=\frac{F c d}{t d}
$$

f.Total kalor briket yang terpakai $\left(Q_{\text {total }}\right)$

Total kalor briket terpakai ditentukan dengan cara mengalikan antara total briket yang terpakai dengan nilai kalor yang terkandung dalam briket tersebut.

2. Implementasi penelitian pendidikan, pada tahap ini briket campuran kulit durian dan tempurung kelapa digunakan sebagai bahan praktikum materi suhu dan kalor. Desain penelitian pendidikan yang digunakan adalah one group design yaitu menggunakan satu kelas yang memiliki kemampuan yang sama/homogen. Adapun desain penelitiannya disajikan pada Tabel 1.

Tabel 1. Rancangan Penelitian

\begin{tabular}{lll}
\hline Pre-test & Perlakuan & Post-test \\
\hline $\mathrm{O}_{1}$ & $\mathrm{X}$ & $\mathrm{O}_{2}$ \\
\hline
\end{tabular}

Keterangan :

X :Pembelajaran dengan model Discovery Learning

$\mathrm{O}_{1} \quad$ : Tes Awal (pre-test)

$\mathrm{O}_{2} \quad$ : Tes Akhir (post-test)

3. Pasca Implementasi, pada tahap ini hasil pre test dan post test dilakukan analisis untuk mengetahui kemampuan kognitif siswa. Peningkatan kemampuan kognitif siswa tentang suhu dan kalor setelah mengunakan model Discovery Learning dapat dilakukn dengan membandingkan hasil tes awal dan tes akhir. Peningkatan yang terjadi sesudah pembelajaran dihitung dengan $\mathrm{g}$ faktor skor (gain dinormalisasi).

Subjek penelitian ini adalah siswa KIR Kelas VII SMP Negeri 15 Kota Bengkulu sebanyak 25 orang, yang dibagi menjadi tiga kelompok, yakni kelompok tinggi, kelompok sedang dan kelompok rendah.

\section{HASIL DAN PEMBAHASAN}

Briket kulit durian dan tempurung kelapa dalam penelitian ini terdiri dari tiga jenis yakni $\mathrm{K} 1, \mathrm{~K} 2$ dan $\mathrm{K} 3$ dengan perbandingan komposisi yang berbeda-beda. Briket K1 terdiri dari $20 \%$ arang kulit durian:80\% tempurung kelapa.

Briket K1 memiliki massa kering setelah penjemuran rata-rata 31,67 gram, tinggi briket $2,1 \mathrm{~cm}$ dan diameter briket $5 \mathrm{~cm}$. Briket $\mathrm{K} 2$ terdiri dari 50\% arang kulit durian: $50 \%$ tempurung kelapa. Briket K2 memiliki massa kering setelah penjemuran rata-rata 29,67 gram, tinggi briket $2,43 \mathrm{~cm}$ dan diameter briket $5 \mathrm{~cm}$. Briket $\mathrm{K} 3$ terdiri dari $80 \%$ arang kulit durian: 20\% tempurung kelapa. Briket K3 memiliki massa kering setelah penjemuran rata-rata 26,67 gram, tinggi briket $3,13 \mathrm{~cm}$ dan diameter briket $5 \mathrm{~cm}$. Nilai kalor dan karakteristik briket campuran kulit durian dan tempurung kelapa dapat dilihat pada Tabel 2.

Tabel 2. Karakteristik dan Nilai kalor briket berbagai komposisi

\begin{tabular}{llll}
\hline $\begin{array}{l}\text { Komposisi } \\
\text { Briket }\end{array}$ & K1 & K2 & K3 \\
\hline $\begin{array}{l}\text { Nilai kalor } \\
\text { Briket } \\
\text { (kal/gram) }\end{array}$ & $7.306,81$ & $6.847,31$ & $6.284,99$ \\
$\begin{array}{l}\text { Kadar Air } \\
\text { Hilang (\%) }\end{array}$ & 20,8 & 25,8 & 33,3 \\
Kerapatan & 0,77 & 0,62 & 0,43
\end{tabular}




\begin{tabular}{lccc}
$\begin{array}{l}\text { Briket }(\mathrm{Kg} / \mathrm{m} 3) \\
\text { Briket } \\
\text { terpakai } \\
\text { (gram) }\end{array}$ & 152 & 155,33 & 173,67 \\
$\begin{array}{l}\text { Waktu } \\
\text { mendidihkan } \\
\text { air (menit) }\end{array}$ & 13,37 & 12,5 & 12,02 \\
$\begin{array}{l}\text { Kecepatan } \\
\text { pembakaran }\end{array}$ & 11,38 & 12,45 & 14,46 \\
$\begin{array}{l}\text { Briket } \\
\text { (g/menit) }\end{array}$ & & & \\
$\begin{array}{l}\text { Total kalor } \\
\text { briket terpakai } \\
\text { ( Kkal) }\end{array}$ & $1.110,63$ & $1.063,60$ & $1.091,50$ \\
\hline
\end{tabular}

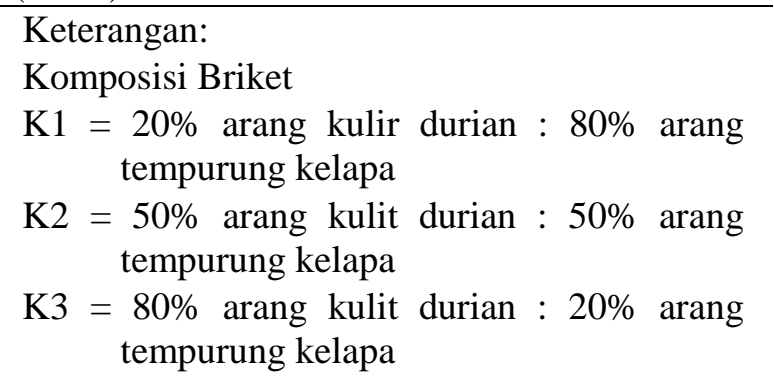

Dari Tabel 2 di atas didapat nilai kalor terendah adalah $6.284,99 \mathrm{kal} / \mathrm{gram}$, terdapat pada briket campuran $80 \%$ arang kulit durian : $20 \%$ arang tempurung kelapa dan nilai kalor tertinggi terdapat pada briket campuran $20 \%$ arang kulit durian : $80 \%$ arang tempurung kelapa. Nilai kalor pada briket ini menunjukkan semakin banyak kandungan tempurung kelapa, maka akan semakin tinggi nilai kalornya. Hal tersebut karena tempurung kelapa memiliki nilai kalor lebih tinggi dibandingkan dengan kulit durian.

Nilai kalor kulit durian pada penelitian ini meningkat setelah dicampur dengan tempurung kelapa, karena tempurung kelapa sebagai pengikat karbon arang kulit durian. Menurut Triono (2006) nilai kalor briket arang akan tinggi apabila nilai kadar karbon terikat pada briket tinggi. Nilai kalor yang dihasilkan dari ketiga briket komposisi arang campuran kulit durian dan tempurung kelapa dalam penelitian ini telah memenuhi Standar Briket Nasional yaitu minimal 5.000 kal/gram (Nurhilal et al 2018).

Pada Tabel 2 ditunjukkan bahwa, kadar air hilang pada saat proses pengeringan briket terkecil terdapat pada komposisi $20 \%$ arang kulit durian : $80 \%$ arang tempurung kelapa sebesar 20,8\% dan tertinggi pada komposisi $80 \%$ arang kulit durian : $20 \%$ arang tempurung kelapa sebesar 33,3\%.
Data tersebut menunjukkan bahwa kadar air semakin tinggi jika jumlah arang kulit durian semakin banyak dan arang tempurung kelapa semakin sedikit. Kadar air yang tinggi disebabkan oleh sifat partikel arang kulit durian yang bersifat higroskopis terhadap air dan udara sekelilingnya. Kadar air sangat erat kaitannya dengan kerapatan briket arang, dimana semakin tinggi kerapatan maka sifat higroskopis briket arang akan semakin berkurang, sehingga daya serap terhadap air semakin kecil. Hal ini disebabkan semakin tinggi kerapatan maka rongga-rongga antar partikel arang akan semakin rapat karena padatnya partikel-partikel tersebut sehingga tidak terdapat cela atau ruang kosong (Bahri, 2007).

Pada Tabel 2 ditunjukkan bahwa, kerapatan briket terkecil terdapat pada komposisi $80 \%$ arang kulit durian : $20 \%$ arang tempurung kelapa sebesar $0,43 \mathrm{gr} / \mathrm{cm} 3$ dan kerapatan tertinggi pada komposisi $20 \%$ arang kulit durian : 80\% arang tempurung kelapa sebesar 0,77. Menurut Hendra (2000) perbedaan jenis bahan baku sangat berpengaruh terhadap besarnya nilai kerapatan briket arang yang dihasilkan. Bahan baku yang memiliki kerapatan tinggi akan menghasilkan briket arang dengan kerapatan tinggi, sedangkan bahan baku dengan kerapatan rendah akan menghasilkan briket arang dengan kerapatan rendah. Kerapatan mempengaruhi nilai kalor, semakin tinggi nilai kerapatan menyebabkan nilai kalor semakin tinggi (Jamilatun, 2008). Pada Tabel 2 menunjukkan bahwa, nilai briket terpakai terkecil untuk mendidihkan air adalah 152 gram terdapat pada komposisi $20 \%$ arang kulit durian : $80 \%$ tempurung kelapa dan tertinggi pada komposisi $80 \%$ arang kulit durian : 20\% arang tempurung kelapa sebesar 173,67 gram. Menurut Fajari (2012) semakin tinggi nilai kalor, maka panas yang dihasilkan semakin tinggi, dan pembakaran akan semakin lama, hal ini sesuai dengan penelitian yang dilakukan peneliti, bahwa semakin tinggi nilai kalor briket akan semakin kecil nilai kecepatan pembakarannya dan briket yang terpakai juga semakin sedikit.

Pada Tabel 2 didapat bahwa briket dengan komposisi $80 \%$ arang kulit durian : $20 \%$ arang tempurung kelapa memiliki waktu tercepat yaitu 12,02 menit dan waktu mendidihkan paling lama adalah 13,37 menit pada briket komposisi $20 \%$ arang kulit durian 
:80\% arang tempurung kelapa. Kecepatan pembakaran briket merupakan banyaknya briket yang terbakar persatuan waktu. Semakin besar nilainya, maka briket akan semakin cepat dan semakin mudah terbakar. Dari Tabel 2 Komposisi briket $80 \%$ arang kulit durian : $20 \%$ arang tempurung kelapa pada memiliki kecepatan pembakaran terbesar yaitu 14,46 gram/menit dan yang terkecil adalah 11,38 gram/menit pada komposisi $20 \%$ arang kulit durian : $80 \%$ arang tempurung kelapa. Ditinjau dari nilai kalor briket, terlihat bahwa semakin tinggi nilai kalornya akan menghasilkan kecepatan pembakaran yang semakin kecil.

Menurut Jamilatun (2008) kecepatan pembakaran dipengaruhi oleh struktur bahan, kandungan karbon terikat dan kekerasan bahan. Kecepatan pembakaran briket berpengaruh terhadap lama pembakaran bahan bakar briekt, dimana semakin besar nilai kecepatan pembakaran akan semakin cepat habis briket terbakar, sebaliknya semakn kecil kecepatan pembakaran briket

Nilai total kalor terpakai yang terkecil adalah komposisi 50\% arang kulit durian : $50 \%$ tempurung kelapa dengan nilai 1.063,6 Kkal dan yang terbesar adalah 1.110,63 Kkal pada komposisi 20\% arang kulit durian : $80 \%$ arang tempurung kelapa. Menurut Jamilatun (2008) bahwa nilai kalor yang tertinggi akan membuat pembakaran lebih efisien sehingga jumlah briket yang digunakan akan semakin hemat dan jumlah kalor yang dihasilkan juga lebih efisien.

\section{Implementasi dalam Pendidikan}

Penelitian ini dilaksanakan di SMP Negeri 15 Kota Bengkulu pada semester genap tahun pelajaran 2018/2019.Sebelum dilaksanakan pembelajaran sesuai dengan perlakuan ,ketiga kelompok belajar dilakukan uji tes awal (pretest) untuk mengetahui kemampuan awal ketiga kelompok subjek penelitian. Untuk mengetahui peningkatan hasil belajar secara kognitif yang diberikan model pembelajaran dengan model Discovery Learning setelah proses pembelajaran ketiga kelompok diberikan tes akhir (posttest).

Pemberian pretest bertujuan untuk mengetahui pemehaman awal peserta didik terhadap materi Suhu dan Kalor, sebelum dilakukan pembelajaran dengan menggunakan model Discovery Learning (DL). Posttest bertujuan untuk mengetahui pemahaman akhir peserta didik mengenai materi Suhu dan Kalor setelah mendapatkan perlakuan berupa pembelajaran dengan menggunakan model Discovery Learning (DL). Soal Pretest dibuat sama dengan soal posttest berjumlah 16 soal pilihan ganda yang diberikan setelah pelajaran berakhir. Hasil pretest dan posttest dapat dilihat pada Gambar 2 berikut ini.

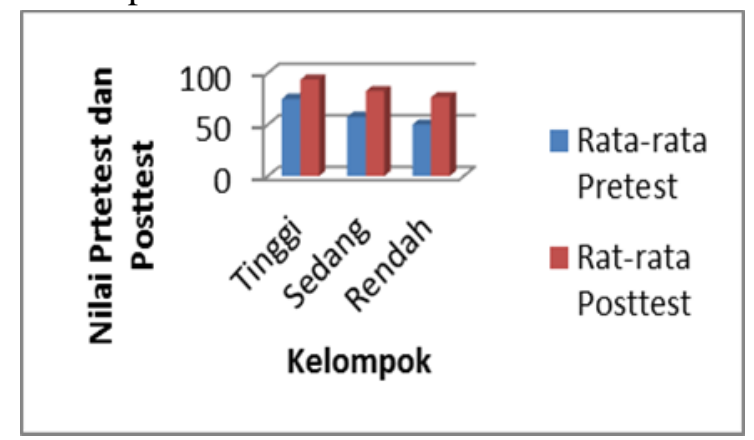

Gambar 2. Grafik nilai pretest dan posttest

Dari Gambar 2 dapat dilihat bahwa masing-masing kelompok mengalami peningkatan rata-rata nilai pretest dan postest. Kelompok tinggi mengalami kanaikan ratarata nilai sebesar 18,75 angka. Kelompok sedang mengalami kenaikan rata-rata nilai sebesar 25 angka. Kelompok rendah mengalami kenaikan rata-rata nilai sebesar 26,56 angka. Berdasarkan data hasil implementasi karakteristik nilai kalor briket campuran kulit durian dan tempurung kelapa sebagai bahan praktikum pada kegiatan pembelajaran suhu dan kalor. Dari hasil analisis di ketahui bahwa penggunaan briket campuran kulit durian dan tempurung kelapa memiliki efektifivitas yang baik dalam meningkatkan kemampuan kognitif yang dicapai siswa SMP N 15 Kota Bengkulu. Kemampuan kognitif mencakup kemampuan mengingat, memahami, menerapkan, menganalisis, mengevaluasi dan mengkreasi. Kemampuan-kemampuan ini erat kaitannya dengan penguasaan materi suhu dan kalor.

Peningkatan hasil belajar siswa dapat dilihat pada grafik nilai $N$-Gain berikut 


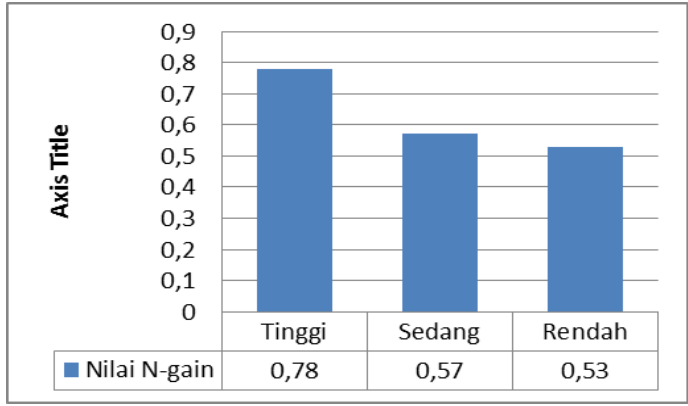

Gambar 3. Grafik Nilai N-Gain

Dari Gambar 3 dapat dilihat bahwa kelompok tinggi memiliki nilai $N$-gain lebih tinggi dari kelompok lainnya sebesar 0,78 dalam kategori tinggi. Kelompok sedang memiliki nilai $N$-gain sebesar 0,57 dalam kategori sedang. Kelompok rendah memiliki nilai $N$-gain paling rendah sebesar 0,53 dalam kategori sedang. Hal ini berarti bahwa terdapat peningkatan hasil belajar kelompok tinggi memiliki peningkatan lebih tinggi dari kelompok lainnya, hasil penelitian ini sesuai dengan hasil penelitian Sudiro et al (2018). Menurut Putri et al (2017) model Discovery Learning dapat meningkatkan hasil belajar siswa pada aspek kognitif (pengetahuan).

\section{KESIMPULAN}

Penelitian yang telah dilakukan dapat ditarik kesimpulan sebagai berikut: Nilai kalor briket campuran kulit durian 20\%: tempurung kelapa $80 \%$ sebesar $7306,81 \mathrm{kal} / \mathrm{gr}$; nilai kalor briket campuran kulit durian 50\%: tempurung kelapa 50\% sebesar $6487,31 \mathrm{kal} / \mathrm{gr}$ dan nilai kalor briket campuran kulit durian $80 \%$ : tempurung kelapa $20 \%$ sebesar 6284,99 $\mathrm{kal} / \mathrm{gr}$ dan implementasi dalam pembelajaran terdapat peningkatan hasil belajar kognitif peserta didik pada kelompok tinggi, sedang dan rendah setelah belajar menggunakan model Discovery Learning.

\section{DAFTAR PUSTAKA}

Bahri, S. (2007). Pemanfaatan Limbah Industri Pengolahan Kayu untuk Pembuatan Briket Arang dalam Mengurangi Pencemaran di Nangroe Aceh Darusalam. Universitas Sumatera Utara.

Elfiano, E.,Subekti, P., Sadil, A. (2014). Analisis Proksimat dan Nilai Kalor pada Briket Bioarang Limbah Ampas Tebu dan Arang kayu. Jurnal APTEK No 1 hal 57-64

Emerhi,E.A. (2011). Physical and Combustion Proporties of Briquettes Produced from Sawdust of Three Hardwood Species and Different Organic Binders. Nigeria: Departement of Forestry and Wildlife, Delta State. Univesity. WWW. Pelagiaresearch Library.com

Fajari, I. (2012). Karakteristik Pembakaran Briket Arang Campuran Sekam Padi dan Serbuk Kayu Serta Implementasinya sebagai Model Pembelajaran Dengan LKS Kimia Berbasis Keterampilan Proses di SMA $N 3$ Lubuk Linggau. Bengkulu. Tesis Pascasarjana Universitas Bengkulu

Halimmatus, S . (2010). Pemanfaatan Limbah Kulit Durian dalam pembuatan Briket Arang sebagai Bahan Bakar Alternatif. Semarang: Fakultas Tehnik Universitas Negari Semarang

Hasbullah., Iskandar, T., Yuniningsih, S.(2018). Identifikasi Nilai Kalor pada Briket Biochar Berbahan Baku Kulit Durian. eUREKA. Jurnal Penelitian Mahasiswa Tehnik Sipil dan Tehnik Kimia 2(1) hal 1-8

Hatta, V.(2007). Manfaat Kulit Durian Selezat Buahnya. Universitas Lampung. Lampung

Hendra,D., Darmawan, S. (2000). Pembuatan Briket Arang Serbuk Gergajian Kayu dengan Penambahan Tempurung Kelapa. Buletin Penelitian Hasil Hutan. Bogor.

Jamilatun, S. (2008). Sifat-sifat Penyalaan dan Pembakaran Briket Biomassa, Briket Batubara dan Arang Kayu. Yogyakarta. Jurnal Rekayasa Proses, Vol 2, No. 2

Nurhilal,O. (2017) .Karakteristik Biobriket Campuran Serbuk Kayu dan Tempurung Kelapa. Bandung:Jurnal Material dan Energi Indonesia Vol 07 No 02(2017) Hal 13-16

Nurhilal, O; Suryaningsih, S. (2018). Pengaruh Komposisi Campuran Sabut dan Tempurung Kelapa Terhadap Nilai Kalor Biobriket dengan Perekat Molase. Bandung: Jurnal Ilmu dan Inovasi Fisika Vol 02 No 01 (2018) 814

Nuriana, W., Anisa, N dan Martana. (2013). Karakteristik Biobriket Kulit Durian 
Sebagai Bahan Bakar Alternatif Terbarukan,Jurnal Teknologi Industri Pertanian 23(1) hal 70-76

Putri, I; Juliani, R; Lestari, N. (2017). Pengaruh Model Pembelajaran Discovery Learning terhadap Hasil Belajar Siswa dan Aktivitas Siswa. Medan. Jurnal Pendidikan Fisika Vol 6.

Sudiro, S., Farid, M., Swistoro, E. (2018). Hubungan antara kedalaman Permukaan Air Tanah dengan Salinitas di Pesisir Pantai Kungkai Baru serta Penggunaan Model Discovery Learning. PENDIPA Journal of Scince Education Vol 2 No 3

Triono. (2006). Karakteristik Briket arang dari campuran serbuk gergaji kayu Afrika (Aesopsis emini) dan Sengon(Paraserianthes falcarita) dengan Penambahan Tempurung Kelapa. Bogor. Institut Pertanian Bogor
Vachlepi, A., Suwardin, D. (2013). Penggunaan Biobriket Sebagai Bahan Bakar Alternatif dalam Pengeringan Karet Alami. Palembang. Balai Penelitian Sumbawa 32(2) hal 65-73

Yuliah, Y; Suryaningsih, S; Ulfi, K.(2017). Penentuan Kadar Air Hilang dan Voltile Matter pada Bio Briket dari Campuran Arang Sekam Padi dan Batok Kelapa. Bandung. Jurnal Ilmu dan Fisika Vol 01, N0 01 51-57 